\title{
Resecting the Dominant Lesion: Patient Outcomes after Surgery and Radiosurgery vs Stand-Alone Radiosurgery in the Setting of Multiple Brain Metastases
}

\section{Maria Punchak ( $\nabla$ maria.punchak@pennmedicine.upenn.edu )}

University of Pennsylvania Health System: Penn Medicine https://orcid.org/0000-0003-1173-7684

\section{Stephen P Miranda}

University of Pennsylvania Health System: Penn Medicine

\section{Alexis Gutierrez}

University of Pennsylvania Health System: Penn Medicine

\section{Steven Brem}

University of Pennsylvania Health System: Penn Medicine

\section{Donald O'Rourke}

University of Pennsylvania Health System: Penn Medicine

John YK Lee

University of Pennsylvania Health System: Penn Medicine

Jacob E. Shabason

University of Pennsylvania Health System: Penn Medicine

\section{Dmitriy Petrov}

University of Pennsylvania Health System: Penn Medicine

\section{Research Article}

Keywords: intracranial metastases, stereotactic radiosurgery, radiation, whole brain radiotherapy

Posted Date: June 10th, 2021

DOl: https://doi.org/10.21203/rs.3.rs-585469/v1

License: (c) (i) This work is licensed under a Creative Commons Attribution 4.0 International License. Read Full License

Version of Record: A version of this preprint was published at Clinical Neurology and Neurosurgery on November 1st, 2021. See the published version at https://doi.org/10.1016/j.clineuro.2021.107016. 


\section{Abstract}

BACKGROUND: Brain metastases are the most common central nervous system (CNS) tumors, occurring in 300,000 people per year in the US. The benefit of surgical resection, over radiosurgery, for dominant lesions remains unclear.

METHODS: The University of Pennsylvania Health System database was retrospectively reviewed for patients presenting with multiple brain metastases from 1/1/16 to $8 / 31 / 18$ with one dominant lesion $\geq 2$ $\mathrm{cm}$ in diameter, who underwent initial treatment with either resection of the dominant lesion or Gamma Knife radiosurgery (GKS). Inclusion criteria were age $\geq 18,>1$ brain metastasis, and presence of a dominant lesion $(>2 \mathrm{~cm})$. We analyzed factors associated with mortality.

RESULTS: 129 patients were identified (surgery $=84, \mathrm{GKS}=45$ ). The median number of intracranial metastases was 3 (IQR: 2-5). The median diameter of the largest lesion was $31 \mathrm{~mm}$ (IQR: 25-38) in the surgery group vs $21 \mathrm{~mm}$ (IQR: 20-24) in the GKS group ( $p<0.001)$. Mortality did not differ between surgery and GKS patients $(69.1 \%$ vs $77.8 \%, p=0.292)$. In a multivariate survival analysis, there was no difference in mortality between the surgery and GKS cohorts (aHR: $1.35,95 \% \mathrm{Cl}: 0.74-2.45 \mathrm{p}=0.32$ ). Pre-operative KPS (aHR: 0.97, 95\% Cl: 0.95-0.99, p=0.004), CNS radiotherapy (aHR: 0.33, 95\% Cl: 0.19-0.56 p<0.001), chemotherapy (aHR: $0.27,95 \% \mathrm{Cl}: 0.15-0.47, \mathrm{p}<0.001$ ), and immunotherapy (aHR: $0.41,95 \% \mathrm{Cl}: 0.25-0.68$, $\mathrm{p}=0.001)$ were associated with decreased mortality.

CONCLUSION: In our institution, patients with multiple brain metastases and one symptomatic dominant lesion demonstrated similar survival after GKS when compared with up-front surgical resection of the dominant lesion.

\section{Introduction}

Brain metastases are the most common central nervous system (CNS) tumors, occurring in 300,000 people per year in the US, far outnumbering cases of primary brain tumors. Approximately 1.7 million people are diagnosed with cancer annually, and of these patients, up to $40 \%$ go on to develop one or more intracranial metastases [1-3]. Moreover, incidence of metastatic brain cancer is increasing due to improved diagnostic testing and systemic therapies that have afforded cancer patients longer survival [4]. Among the most common cancers to metastasize to the brain are lung, breast, melanoma, and genitourinary tract cancers [5]. Only $10-20 \%$ of brain metastases present as solitary tumors; the vast majority occur as multiple metastases [6].

Historically, due to inadequate control of systemic disease as well as poor performance status, patients with multiple brain metastases had limited life expectancy, and whole brain radiotherapy (WBRT) with corticosteroids remained standard of care [7-10]. This has changed over the past few decades. Advances in neurosurgical techniques, improved surveillance, more effective systemic therapies, and the advent of stereotactic radiosurgery (SRS) have broadened the therapeutic options for patients with 
multiple metastases [11]. There is evidence in support of both SRS and surgical resection in the treatment of solitary brain metastases, with similar reported rates of overall survival $[5,9,10,12-16]$.

Indications for surgery for multiple, synchronous metastases remain highly debated. Traditionally, surgical resection is reserved for patients with better performance status, stable systemic disease, and symptomatic mass effect from a dominant lesion, with adjuvant SRS to the operative bed and additional smaller metastases $[2,8,17,18]$. Recent evidence has demonstrated the efficacy of SRS without upfront surgery for improving both tumor control and survival in the setting of multiple metastases, but direct comparisons with conventional surgical resection are few in number [19-23]. A limited number of retrospective reviews have reported survival benefit after resection of multiple metastases, but there is a great need for higher-quality evidence reflecting contemporary practice patterns $[5,18,24,25]$.

Given the conflicting evidence, we analyzed factors associated with mortality in patients with multiple intracranial metastases with one dominant lesion undergoing surgery followed by SRS or standalone SRS $[2,18]$.

\section{Methods}

\section{UPHS Protocol for Management of Multiple Intracranial Metastases}

Within University of Pennsylvania Health System (UPHS), patients who present with multiple metastases, and at least one dominant lesion ( $>=/ 2 \mathrm{~cm}$ in diameter) causing profound vasogenic edema and neurologic deficits, are offered surgical intervention upfront. Patients with a dominant lesion, but without profound symptoms, are offered SRS using Gamma Knife radiosurgery (GKS) to all lesions. Nearly all patients who undergo surgical resection undergo GKS to the tumor bed as well as unresected metastases 4-6 weeks after surgical resection. Occasionally, those with poor functional status and/or leptomeningeal disease are offered WBRT, while a select few undergo CyberKnife (CK). For the purposes

of our manuscript, both patients who underwent radiotherapy after surgical resection and those who underwent additional radiotherapy after upfront GKS, were categorized as having undergone "adjuvant or repeat radiotherapy". Those who required either additional surgery after primary resection or after upfront GKS, were categorized as receiving "adjuvant or repeat surgery".

\section{Patient Selection}

The UPHS database was queried for patients presenting with multiple brain metastases from 1/1/16 to $8 / 31 / 18$, and who underwent up-front resection of a symptomatic dominant lesion vs Gamma Knife radiosurgery (GKS). Inclusion criteria was age $\geq 18$, presence of $>1$ brain metastasis, and a dominant lesion $\geq 2 \mathrm{~cm}$ in diameter. Patients with prior craniotomies, WBRT, or GKS were excluded. We analyzed factors associated with survival.

Data Collection 
The Department of Neurosurgery oncology databases were queried for patients who underwent craniotomy for tumor within UPHS from January 1, 2016 to August 31, 2018, using the following Current Procedural Terminology (CPT) codes: 61500, 61510, 61518. 1516 patients were identified using the above CPT codes. The electronic medical records were reviewed to exclude patients that underwent craniotomies for indications other than brain tumors. The remaining 965 patients were reviewed to exclude those with diagnoses of primary brain tumor, including glioma and meningioma. The remaining 365 patients were screened for those presenting with solitary metastasis on pre-operative imaging. 149 patients were identified who underwent craniotomy in the setting of two or more brain metastases. After excluding patients whose dominant lesions were $<2 \mathrm{~cm}$ in largest dimension, 101 total patients met our inclusion criteria prior to neurosurgical intervention in the specified timeframe. 84 of these had complete information and follow up upon review of the medical record. Figure 1 contains a flow diagram for inclusion within the patient cohort.

The Department of Neurosurgery Gamma Knife database was queried for patients who presented within the same time frame with a diagnosis of multiple brain metastases, who underwent solely Gamma Knife treatment. Any patients who had undergone prior up-front surgical resection were excluded. Imaging was reviewed to confirm the presence of a "dominant lesion", defined as $2 \mathrm{~cm}$ or greater, to best match the primary cohort of interest. 45 total patients were identified.

Variables of interest were reviewed and collected into a password protected database using Excel V16.25 (Microsoft, 2019).

Data Analysis

Data was analyzed in Stata 12.1 (StataCorp LLC, College Station, Texas, USA). Demographic, clinical characteristics, and outcomes of patients were analyzed using descriptive statistics. Differences in the demographics, clinical characteristics and outcomes of interest between the two patient cohorts (GKS vs surgery) were determined using Mann-Whitney $U$ test for continuous variables and $c^{2}$ test for categorical variables. Cox proportional hazards regression model was then used to perform a survival analysis to assess association between variables of interest and overall survival, taking into account possible confounders. The proportional hazards assumption was checked to ensure model accuracy using Schoenfeld residuals. Kaplan-Meier survival curves were used to further analyze post-intervention survival in patients undergoing GKS vs surgery, those receiving adjuvant CNS radiotherapy post primary intervention and those receiving adjuvant chemotherapy. Sensitivity analysis was performed, excluding patients in whom the largest metastasis was $>3.5 \mathrm{~cm}$ and $>3.0 \mathrm{~cm}$ from the cohort. Statistical significance was defined as $p<0.05$.

\section{Ethical Considerations}

All patient information was de-identified and information was stored in a password protected database. All research was conducted in accordance with the standards of the University of Pennsylvania Institutional Review Board. 


\section{Results}

\section{Demographics \& Clinical Characteristics}

129 patients were identified (surgery=84, GKS=45). Median age was 60 year (IQR: $52-67$ )), and $52.7 \%$ were female. The most common primary cancer was lung (48.1\%). The median number of metastases was 3 (IQR: 2-5), and the median diameter of the largest lesion was $26 \mathrm{~mm}$ (IQR: 21-35). In 73.6\% of patients the largest metastasis was supratentorial. The median pre-intervention Karnofsky Performance Status (KPS) score was 80 (IQR: 70-90). Among all patients, most were classified into recursive partitioning analysis (RPA) class II (52.7\%). There was no statistically significant difference in demographics, total number of CNS metastases, location of metastases, pre-intervention KPS scores and RPA class between surgery and GKS cohorts (Table 1). The median diameter of the largest metastasis was slightly larger for the surgery cohort compared to GKS, $31 \mathrm{~mm}$ (IQR 25-38) vs 21 (IQR: 20-24), respectively $(p<0.001)$ (Table 1$)$. Patients within the surgery cohort underwent adjuvant or repeat CNS radiotherapy more frequently than those within the GKS cohort $(78.6 \%$ vs $40.0 \%$, respectively; $p<0.001)$. There was other difference between surgery and GKS cohorts in the adjuvant treatments received (additional surgery, chemotherapy or immunotherapy).

\section{Outcomes}

The median follow up period was 23 months (IQR: 10-50). The median change in KPS pre and postintervention was -10 (IQR: -20 to 5) in the surgery group, compared to 0 (IQR: -20 to 10) in the GKS group $(p=0.16)$. During the follow up period, $40.3 \%$ of patients transitioned to hospice. Overall mortality was $69.1 \%$ in the surgery group and $77.8 \%$ in the GKS group $(p=0.29)$. Overall median post-intervention survival was 6.9 months (IQR: 2.9-12.6) among the surgery group, compared to 8.5 months (IQR: 2.813.4) among the GKS group ( $p=0.52)$ (Table 2$)$.

\section{Association Analysis}

In a univariate association analysis, there was no difference in overall survival between patients undergoing surgery vs those receiving GKS to the dominant metastasis $(p=0.29)$. Adjuvant CNS radiation post primary intervention, including additional GKS, Cyberknife (CK) or whole brain radiation therapy $(p=0.007)$, chemotherapy $(p=0.002)$ and immunotherapy $(p<0.001)$ were associated with increased survival (Table 3 ).

Using the Cox proportional hazards model which adjusted for confounders (age, gender, primary cancer, total number of metastases, metastasis location, metastasis diameter, preoperative KPS, RPA class, additional post-intervention treatment), there was no difference in overall survival between surgery and GKS cohorts (aHR: 1.35, 95\% Cl:0.74-2.45, p=0.32). Pre-operative KPS (aHR: 0.97, 95\% Cl: 0.95-0.99, $\mathrm{p}=0.004$ ), adjuvant CNS radiotherapy (aHR: $0.33,95 \% \mathrm{Cl}: 0.19-0.56, \mathrm{p}=<0.001)$, adjuvant chemotherapy (aHR: 0.27, 95\% Cl: 0.15-0.47, p=<0.001), and immunotherapy (aHR: 0.41, 95\% Cl: 0.25-0.68, p=0.001) were associated with decreased mortality (Table 3). Metastatic melanoma (aHR: 5.41, 95\% Cl: 1.82-16.1, 
$\mathrm{p}=0.002$ ), and other primary cancers besides breast and lung (aHR: $2.90,95 \% \mathrm{Cl}: 1.15-7.27, \mathrm{p}=0.02$ ) were associated with increased mortality. In the sensitivity analysis, excluding patients with a dominant metastasis $>3.5 \mathrm{~cm}$ and $>3.0 \mathrm{~cm}$ did not lead to a difference in overall survival using the multivariate model ( $p=0.51$ and $p=0.43$, respectively) (Supplemental Table 1 ).

Survival curves for patient undergoing surgery vs GKS as primary intervention for a dominant metastasis are represented in Figure 2a. Meanwhile, Figures $2 b, 2 c$ and $2 d$ demonstrate survival in patients receiving adjuvant CNS radiation, chemotherapy, and immunotherapy, respectively.

\section{Discussion}

Presently there is no standardized pathway for the management of multiple brain metastases. Treatment decision-making in this population is not straightforward, as patients can present with metastases of varying size and location, and variable severity of systemic disease [6, 26]. Surgery and SRS have demonstrated favorable outcomes, both as stand-alone therapies and in combination $[2,13,15,18,21$, $22,24,26,27]$. Current CNS guidelines for the treatment of multiple brain metastases list surgical resection, WBRT and SRS as viable first-line therapies, however there are few direct comparisons of upfront resection followed by SRS versus only SRS in this setting $[7,28]$. Guidelines broadly state that surgical resection or debulking could be favorable among patients with good control of systemic disease whose lesions are symptomatic and accessible by craniotomy, but patient selection is left to the discretion of treating physicians $[7,12]$. Traditionally, prevailing wisdom often favors surgical resection for symptomatic dominant lesions to relieve mass effect, while SRS is reserved for lesions that are surgically inaccessible and for patients with poor control of systemic disease [29].

In this single-institution, retrospective, cohort study, we compared surgery followed by GKS with standalone GKS for patients with multiple CNS metastases and one dominant lesion and found no significant difference in survival. Moreover, quality of life was not affected by treatment modality, as KPS scores did not differ significantly at follow-up for the two cohorts. As expected, pre-intervention KPS, adjuvant chemotherapy and immunotherapy as well as adjuvant or repeat radiotherapy were associated with improved survival.

There are few series reporting outcomes on surgical resection of multiple intracranial metastases, although evidence to date suggests they are comparable to those reported for patients undergoing resection of a single metastasis $[7,18,24,27]$. Some groups have reported a survival benefit for patients with multiple metastases if all lesions are able to be resected $[2,18,26]$. Our findings suggest that upfront SRS to multiple metastases in the setting of a dominant lesion may be as efficacious as surgery followed by GKS in achieving long-term survival. Certain patients - particularly those requiring tissue diagnosis, and those with lesions $>4 \mathrm{~cm}$ in diameter which would otherwise not be able to be adequately treated with radiation alone - should still be treated with surgery upfront $[12,30]$. However, in patients not meeting these prerequisites, SRS may be preferable given its similar long term outcomes and significantly less invasive nature. 
In fact, SRS can lead to dramatic size reductions in the size of a dominant lesion as seen in Supplemental Figure 1, and requires shorter recovery time and offers fewer complications compared to surgery. In fact, unlike GKS, surgery also carries the risk of post-operative complications, including infection, as shown in Supplemental Figure 2. Avoiding the need for postsurgical recovery allows for rapid initiation of systemic therapies $[12,30]$. As demonstrated in our study, only preoperative functional status and systemic therapy is associated with a decrease in all-cause mortality in patients with multiple intracranial metastases. Thus, it can be inferred that initiating systemic treatment more quickly, may promote survival in this patient population.

In it important to note that in certain cases, upfront SRS may predispose patients to increased risk of death from neurological causes. These patients may require neurosurgery after SRS due to postprocedure complications, such a radiation changes or rapid progression of CNS disease, as shown in Supplemental Figure $3[3,7]$.

In recent years, there has been a move toward adopting the practice of pre-operative SRS within 48 hours of surgical resection, which is not yet common practice at UPHS. Pre-operative SRS has been shown to decrease incidence of leptomeningeal (LMD) disease progression at one year follow up [31]. This finding suggests that preoperative SRS is capable of sterilizing tumor cells that could be spilled at the time of surgery and does not confer a higher risk of LMD than WBRT, which treats the entire intracranial CSF space.

There are several limitations to our study. Firstly, our small sample size limits the strength of our findings - in fact, a combined sample of 190 patients would have been necessary to detect a statistically significant different in mortality between the two cohorts. Secondly, while patients in the GKS and surgery cohorts had no significant difference in their background characteristics, it is possible additional confounders were missed. Moreover, this study is not a perfect comparison of surgery followed by GKS versus GKS as stand-alone treatment options, as there was a selection bias toward smaller diameter of dominant metastases in the GKS cohort, although our sensitivity analysis demonstrated excluding patients with larger dominant lesions did not lead to a survival difference between the groups. Furthermore, in the study period, $20 \%$ of patients in the surgical cohort did not undergo follow-up GKS, Cyberknife, or WBRT either due to rapid progression of cancer post surgery excluding them from additional treatment or due to loss to follow up. While approximately $80 \%$ of the surgical cohort received adjuvant GKS/WBRT/CK, 20\% required repeat resection, which may have influenced overall mortality as well. The high repeat resection rate and lack of universal postop radiotherapy limits the generalizability of the results. In contrast, the up-front GKS cohort rarely required late-surgery or additional GKS.

In conclusion, in this single institution, retrospective cohort study, we found no significant difference in survival or postoperative performance status between patients with multiple CNS metastases and one dominant lesion who underwent surgery followed by GKS versus standalone GKS. In patients with advanced extra-CNS disease and medical comorbidities, the additional risks of anesthesia and open surgery for a dominant lesion may not be warranted. On the basis of this single-center retrospective 
analysis, SRS may offer a comparable, safer alternative for this population, and allow for the more rapid initiation of life prolonging systemic therapies.

\section{Declarations}

Funding: Not applicable.

Conflict of Interest: None.

Availability of Data and Material: All data generated or analyzed during this study are included in this published article (and its supplementary information files).

Code Availability: All data was analyzed and coded in Stata.

Author Contributions: All authors contributed to the study conception and design. MP, AG performed the data extraction and analysis. All authors have contributed to and approved the final manuscript.

Ethics Approval: All research was conducted in accordance with the standards of the University of Pennsylvania Institutional Review Board.

Consent to Participate: Not applicable.

Consent for Publication: Not applicable.

\section{References}

1. American Cancer Society (2018) Cancer Facts. Am Cancer Soc. doi:10.1182/blood-2015-12-687814

2. Smith T, Lall R, Lall R et al (2014) Survival after surgery and stereotactic radiosurgery for patients with multiple intracranial metastases: Results of a single-center retrospective study. J Neurosurg 121:839-845. doi:10.3171/2014.4.JNS13789

3. Patchell R (2003) The management of brain metastases. Cancer Treat Rev 29:533-540

4. Nayak L, Lee EQ, Wen PY (2012) Epidemiology of brain metastases. Curr Oncol Rep 14:48-54. doi:10.1007/s11912-011-0203-y

5. Al-Shamy G, Sawaya R (2009) Management of brain metastases: The indispensable role of surgery. J Neurooncol 92:275-282. doi:10.1007/s11060-009-9839-y

6. American Brain Tumor Association (2018) Metastatic Brain Tumors

7. Bindal AK, Bindal RK, Hess KR et al (1996) Surgery versus radiosurgery in the treatment of brain metastasis. J Neurosurg 84:748-754. doi:10.3171/jns.1996.84.5.0748

8. Dutta SW, Sheehan JP, Niranjan A et al (2018) Evolution in the role of stereotactic radiosurgery in patients with multiple brain metastases: An international survey. J Clin Neurosci 57:6-12.

doi:10.1016/j.jocn.2018.08.029 
9. Gaspar LE, Werner-wasik M, Andrews DW et al (2004) Whole brain radiation therapy with or without stereotactic radiosurgery boost for patients with one to three brain metastases: Phase III results of the RTOG 9508 randomised trial Whole brain radiation therapy with or without stereotactic radiosurgery boo. Lancet 363:1665-1672. doi:10.1016/S0140-6736(04)16250-8

10. Stafinski T, Jhangri GS, Yan E, Menon D (2006) Effectiveness of stereotactic radiosurgery alone or in combination with whole brain radiotherapy compared to conventional surgery and/or whole brain radiotherapy for the treatment of one or more brain metastases: A systematic review and metaanalysis. Cancer Treat Rev 32:203-213. doi:10.1016/j.ctrv.2005.12.009

11. Sheehan J, Niranjan A, Flickinger JC et al (2004) The expanding role of neurosurgeons in the management of brain metastases. Surg Neurol 62:32-40. doi:10.1016/j.surneu.2003.10.033

12. Suh JH (2010) Stereotactic radiosurgery for the management of brain metastases [2]. N Engl J Med 362:1119-1127. doi:10.1056/NEJMc1005003

13. Nieder C, Grosu AL, Gaspar LE (2014) Stereotactic radiosurgery (SRS) for brain metastases: A systematic review. Radiat Oncol 9:1-9. doi:10.1186/1748-717X-9-155

14. Fuentes R, Osorio D, Expósito Hernandez J et al (2018) Surgery versus stereotactic radiotherapy for people with single or solitary brain metastasis. Cochrane Database Syst Rev.

doi:10.1002/14651858.CD012086.pub2

15. Linskey ME, Andrews DW, Asher AL et al (2010) The role of stereotactic radiosurgery in the management of patients with newly diagnosed brain metastases: A systematic review and evidencebased clinical practice guideline. J Neurooncol 96:45-68. doi:10.1007/s11060-009-0073-4

16. Kocher M, Soffietti R, Abacioglu U et al (2011) Adjuvant whole-brain radiotherapy versus observation after radiosurgery or surgical resection of one to three cerebral metastases: Results of the EORTC 22952-26001 study. J Clin Oncol 29:134-141. doi:10.1200/JC0.2010.30.1655

17. O’Neill BP, Iturria NJ, Link MJ et al (2003) A comparison of surgical resection and stereotactic radiosurgery in the treatment of solitary brain metastases. Int J Radiat Oncol Biol Phys 55:11691176. doi:10.1016/S0360-3016(02)04379-1

18. Bindal RK, Sawaya R, Leavens ME, Lee JJ (1993) Surgical treatment of multiple brain metastases. J Neurosurg 79:210-216. doi:10.3171/jns.1993.79.2.0210

19. Yy S, Iwk T, Kh L et al (2016) Surgery or radiosurgery plus whole brain radiotherapy versus surgery or radiosurgery alone for brain metastases. Cochrane Database Syst Rev doi.

10.1002/14651858.CD009454.pub2.www.cochranelibrary.com

20. Kraft J, Zindler J, Minniti G et al (2019) Stereotactic Radiosurgery for Multiple Brain Metastases. Curr Treat Options Neurol. doi:10.1007/s11940-019-0548-3

21. Kalani MS, Filippidis AS, Kalani MA et al (2010) Gamma Knife surgery combined with resection for treatment of a single brain metastasis: preliminary results. J Neurosurg 113:90-96

22. Jagannathan J, Yen C, Ray D et al (2009) Gamma Knife radiosurgery to the surgical cavity following resection of brain metastases. J Neurosurg 111:431-438 
23. Elaimy AL, Mackay AR, Lamoreaux WT et al (2011) Clinical Outcomes of Stereotactic Radiosurgery in the Treatment of Patients with Metastatic Brain Tumors. World Neurosurg 75:673-683. doi:10.1016/J.WNEU.2010.12.006

24. Paek SH, Audu PB, Sperling MR et al (2005) Reevaluation of surgery for the treatment of brain metastases: Review of 208 patients with single or multiple brain metastases treated at one institution with modern neurosurgical techniques. Neurosurgery 56:1021-1033. doi:10.1227/01.NEU.0000158321.90608.BE

25. Kalkanis SN, Kondziolka D, Gaspar LE et al (2010) The role of surgical resection in the management of newly diagnosed brain metastases: A systematic review and evidence-based clinical practice guideline. J Neurooncol 96:33-43. doi:10.1007/s11060-009-0061-8

26. Schackert G, Lindner C, Petschke S et al (2013) Retrospective study of 127 surgically treated patients with multiple brain metastases: Indication, prognostic factors, and outcome. Acta Neurochir (Wien) 155:379-387. doi:10.1007/s00701-012-1606-8

27. Iwadate $Y$, Namba $H$, Yamaura A (2000) Significance of surgical resection for the treatment of multiple brain metastases. Anticancer Res 20:573-577

28. Ammirati M, Nahed BV, Andrews D et al (2019) Congress of Neurological Surgeons Systematic Review and Evidence-Based Guidelines on Treatment Options for Adults with Multiple Metastatic Brain Tumors. Clin Neurosurg 84:E180-E182. doi:10.1093/neuros/nyy548

29. Ewend MG, Morris DE, Carey LA et al (2008) Guidelines for the initial management of metastatic brain tumors: Role of surgery, radiosurgery, and radiation therapy. JNCCN J Natl Compr Cancer Netw 6:505-514. doi:10.6004/jnccn.2008.0038

30. Shen CJ, Lim M, Kleinberg LR (2016) Controversies in the Therapy of Brain Metastases: Shifting Paradigms in an Era of Effective Systemic Therapy and Longer-Term Survivorship. Curr Treat Options Oncol. doi:10.1007/s11864-016-0423-3

31. Prabhu RS, Patel KR, Press RH et al (2019) Preoperative vs postoperative radiosurgery for resected brain metastases: A review. Clin Neurosurg 84:19-29. doi:10.1093/neuros/nyy146

\section{Tables}


Table 1. Background characteristics of patient cohort $(n=129)$.

\begin{tabular}{|c|c|c|c|c|}
\hline & $\begin{array}{l}\text { Total } \\
\mathrm{n}(\%)\end{array}$ & $\begin{array}{c}\text { Surgery Cohort } \\
\mathrm{n}(\%)\end{array}$ & $\begin{array}{c}\text { Gamma Knife Cohort } \\
n(\%) \\
\end{array}$ & P-value \\
\hline & $129(100 \%)$ & $84(65.1 \%)$ & $45(34.9 \%)$ & \\
\hline \multicolumn{5}{|l|}{ Gender } \\
\hline Female & $68(52.7 \%)$ & $43(51.2 \%)$ & $25(55.6 \%)$ & 0.64 \\
\hline Breast & $17(13.2 \%)$ & $11(13.1 \%)$ & $6(13.3 \%)$ & \multirow{4}{*}{0.58} \\
\hline Lung & $62(48.1 \%)$ & $38(45.2 \%)$ & $24(53.3 \%)$ & \\
\hline Melanoma & $21(16.3 \%)$ & $13(15.5 \%)$ & $8(17.8 \%)$ & \\
\hline Other & $29(22.5 \%)$ & $22(26.2 \%)$ & $7(15.6 \%)$ & \\
\hline Diameter (largest metastasis, m m) (median [IQR]) & $26[21-35]$ & $31[25-38]$ & $21[20-24]$ & $<0.001$ \\
\hline Pre-op KPS (median [IQR]) & $80[70-90]$ & $80[70-90]$ & $80[70-90]$ & 0.75 \\
\hline \multicolumn{5}{|l|}{ RPA Class } \\
\hline 1 & $43(33.3 \%)$ & $32(38.1 \%)$ & $11(24.4 \%)$ & \multirow{3}{*}{0.29} \\
\hline II & $68(52.7 \%)$ & $41(48.8 \%)$ & $27(60.0 \%)$ & \\
\hline III & $18(14.0 \%)$ & $11(13.1 \%)$ & $7(15.6 \%)$ & \\
\hline \multicolumn{5}{|l|}{ Adjuct Treatment } \\
\hline Adjuvant or Repeat Surgery & $17(13.2 \%)$ & $15(17.9 \%)$ & $2(4.4 \%)$ & 0.03 \\
\hline Adjuvant or Repeat Radiotherapy & $84(65.1 \%)$ & $66(78.6 \%)$ & $18(40.0 \%)$ & $<0.001$ \\
\hline
\end{tabular}

Table 2. Outcomes of interest $(n=129)$.

\begin{tabular}{|c|c|c|c|c|}
\hline & $\begin{array}{l}\text { Total } \\
\mathrm{n}(\%)\end{array}$ & $\begin{array}{c}\text { Surgery Cohort } \\
\mathrm{n}(\%)\end{array}$ & $\begin{array}{c}\text { Gamma Knife Cohort } \\
n(\%)\end{array}$ & P-value \\
\hline \multicolumn{5}{|l|}{ Outcomes } \\
\hline Follow Up, months (median [IQR]) & $23[10-50]$ & $23.5[10-61]$ & $22[14-36]$ & 0.73 \\
\hline Change in KPS & $-10[-20-10]$ & $-10[-20-5]$ & $0[-20-10]$ & 0.16 \\
\hline Hospice & $52(40.3 \%)$ & $34(40.5)$ & $18(40.0 \%)$ & 0.96 \\
\hline Overall Mortality & $93(72.1 \%)$ & $58(69.1 \%)$ & $35(77.8 \%)$ & 0.29 \\
\hline Post-intervention Survival, months (median [IQR]) & $7.4[2.8-13.0]$ & $6.9[2.9-12.6]$ & $8.5[2.8-13.4]$ & 0.52 \\
\hline
\end{tabular}


Table 3. Factors associated with mortality $(n=129)$.

\begin{tabular}{|c|c|c|c|c|c|}
\hline & \multicolumn{2}{|c|}{ Outcome } & \multirow{2}{*}{ P-value } & \multirow{2}{*}{$\begin{array}{c}\text { Adjusted } \\
\mathrm{HR}(95 \% \mathrm{Cl})\end{array}$} & \multirow{2}{*}{ P-value } \\
\hline & Dead, $\mathbf{n}(\%)$ & Alive, $\mathbf{n}(\%)$ & & & \\
\hline Total & $93(72.1 \%)$ & $36(31 . \%)$ & & & \\
\hline Age (median [IQR]) & $60[53-67]$ & $60.5[51-65]$ & 0.57 & $0.99(0.97-1.01)$ & 0.38 \\
\hline \multicolumn{6}{|l|}{ Gender } \\
\hline $\begin{array}{l}\text { Male } \\
\text { Female }\end{array}$ & $\begin{array}{l}44(72.1 \%) \\
49(72.1 \%)\end{array}$ & $\begin{array}{l}17(27.9 \%) \\
19(28.0 \%)\end{array}$ & 0.99 & $1.15(0.71-1.86)$ & 0.56 \\
\hline \multicolumn{6}{|l|}{ Primary Cancer } \\
\hline $\begin{array}{l}\text { Breast } \\
\text { Lung } \\
\text { Melanoma } \\
\text { Other } \\
\end{array}$ & $\begin{array}{l}10(58.8 \%) \\
47(75.8 \%) \\
14(66.7 \%) \\
22(75.9 \%) \\
\end{array}$ & $\begin{array}{c}7(41.2 \%) \\
15(24.2 \%) \\
7(33.3 \%) \\
7(24.1 \%) \\
\end{array}$ & 0.49 & $\begin{array}{c}- \\
1.78(0.71-4.47) \\
5.41(1.82-16.1) \\
2.90(1.15-7.27) \\
\end{array}$ & $\begin{array}{c}- \\
0.22 \\
0.002 \\
0.02\end{array}$ \\
\hline \# Metastases (median [IQR]) & $3[2-5]$ & $3[2-4.5]$ & 0.93 & $1.02(0.98-1.05)$ & 0.37 \\
\hline \multicolumn{6}{|l|}{ Location of Largest Volume Met } \\
\hline \begin{tabular}{|l|} 
Supratentorial \\
Posterior Fossa \\
\end{tabular} & $\begin{array}{l}66(69.5 \%) \\
27(79.4 \%) \\
\end{array}$ & $\begin{array}{c}29(30.5 \%) \\
7(20.6 \%) \\
\end{array}$ & 0.27 & $1.23(0.70-2.14)$ & 0.47 \\
\hline Diameter (largest metastasis, mm) (median [IQR]) & $26[21-34]$ & $26[21-28]$ & 0.7 & $0.99(0.97-1.01)$ & 0.44 \\
\hline Pre-op KPS (median [IQR]) & $80[70-90]$ & $80[70-95]$ & 0.12 & $0.97(0.95-0.99)$ & 0.004 \\
\hline \multicolumn{6}{|l|}{ RPA Class } \\
\hline $\begin{array}{l}\text { I } \\
\text { II } \\
\text { III } \\
\end{array}$ & $\begin{array}{l}33(76.7 \%) \\
47(69.1 \%) \\
13(72.2 \%) \\
\end{array}$ & $\begin{array}{c}10(23.3 \%) \\
21(30.9 \%) \\
5(27.8 \%) \\
\end{array}$ & 0.68 & $0.76(0.48-1.20))$ & 0.24 \\
\hline \multicolumn{6}{|l|}{ Adjunct Treatment } \\
\hline $\begin{array}{l}\text { Adjuvant or Repeat Surgery } \\
\text { Adjuvant or Repeat Radiotherapy } \\
\text { Chemotherapy } \\
\text { Immunotherapy }\end{array}$ & $\begin{array}{l}14(82.4 \%) \\
54(64.3 \%) \\
59(64.1 \%) \\
48(60.0 \%) \\
\end{array}$ & $\begin{array}{c}3(17.7 \%) \\
30(35.7 \%) \\
33(35.9 \%) \\
32(40.0 \%) \\
\end{array}$ & $\begin{array}{c}0.31 \\
0.007 \\
0.002 \\
<0.001\end{array}$ & $\begin{array}{l}0.85(0.43-1.67) \\
0.33(0.19-0.56) \\
0.27(0.15-0.47) \\
0.41(0.25-0.68)\end{array}$ & $\begin{array}{c}0.64 \\
<0.001 \\
<0.001 \\
0.001 \\
\end{array}$ \\
\hline \multicolumn{6}{|l|}{ Intervention } \\
\hline $\begin{array}{l}\text { Gamma Knife } \\
\text { Surgery }\end{array}$ & $\begin{array}{l}35(77.8 \%) \\
58(69.1 \%)\end{array}$ & $\begin{array}{l}10(22.2 \%) \\
26(31.0 \%)\end{array}$ & 0.29 & $1.35(0.74-2.45)$ & 0.32 \\
\hline
\end{tabular}

\section{Figures}




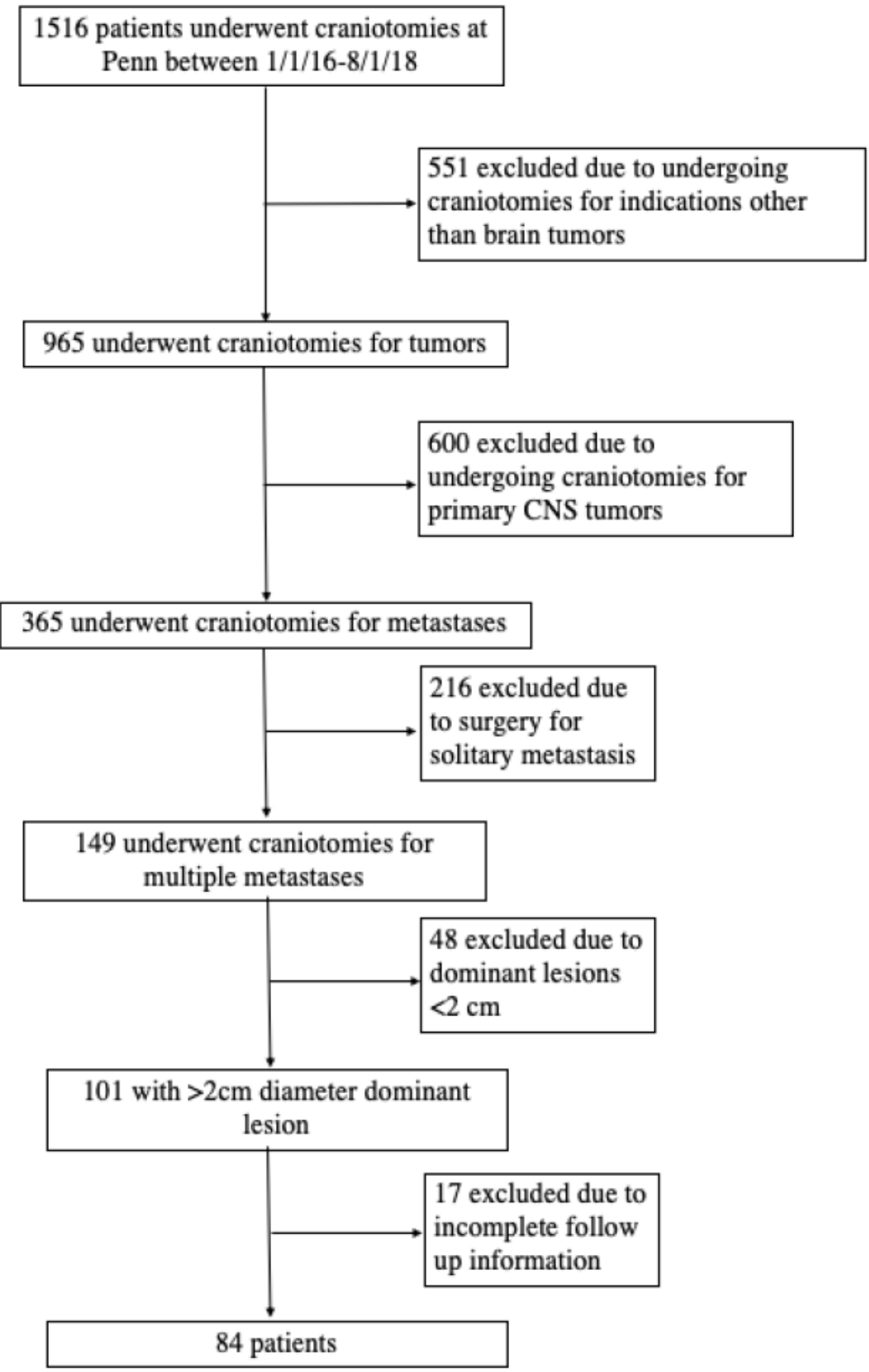

Figure 1

Screening for surgical patients cohort. 
A. GKS vs. Surgery

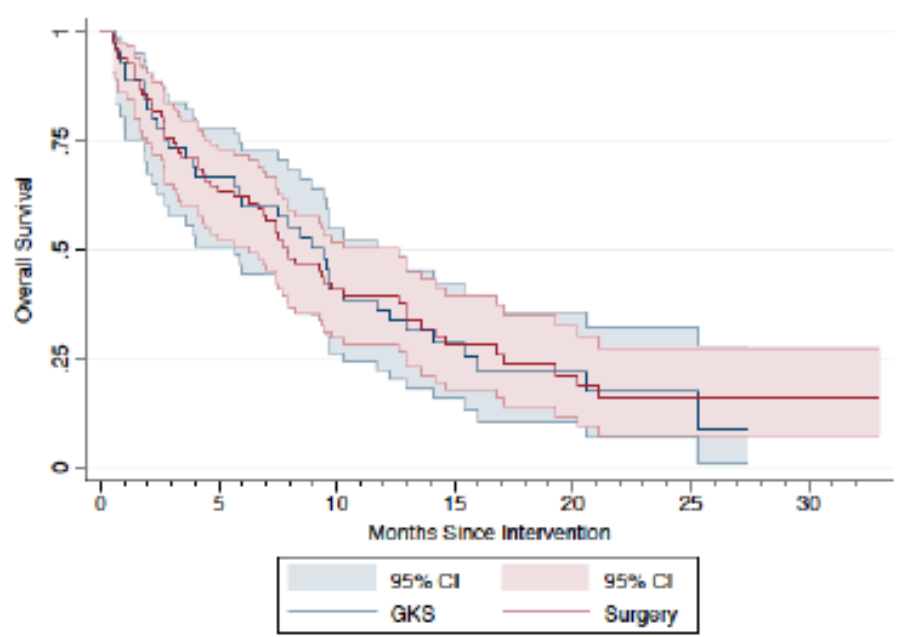

C. Adjuvant systemic chemotherapy vs. No chemotherapy

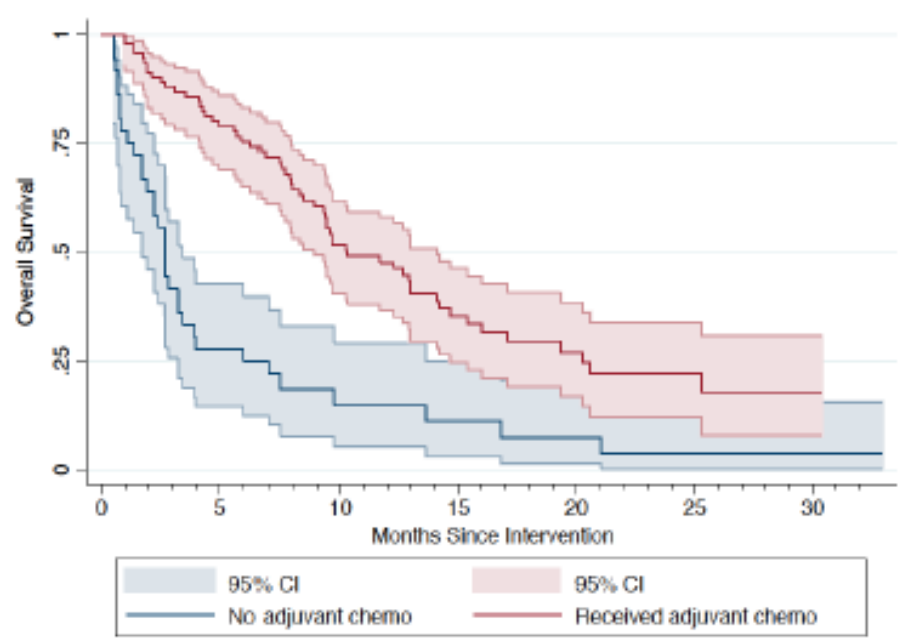

B. CNS radiation vs. No CNS radiation

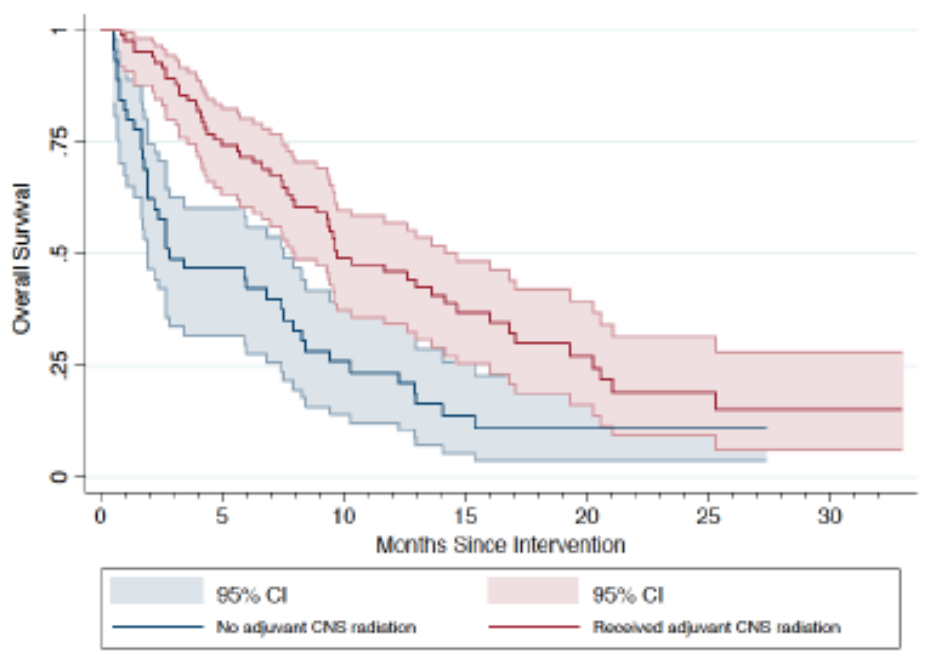

D. Immunotherapy vs. No immunotherapy

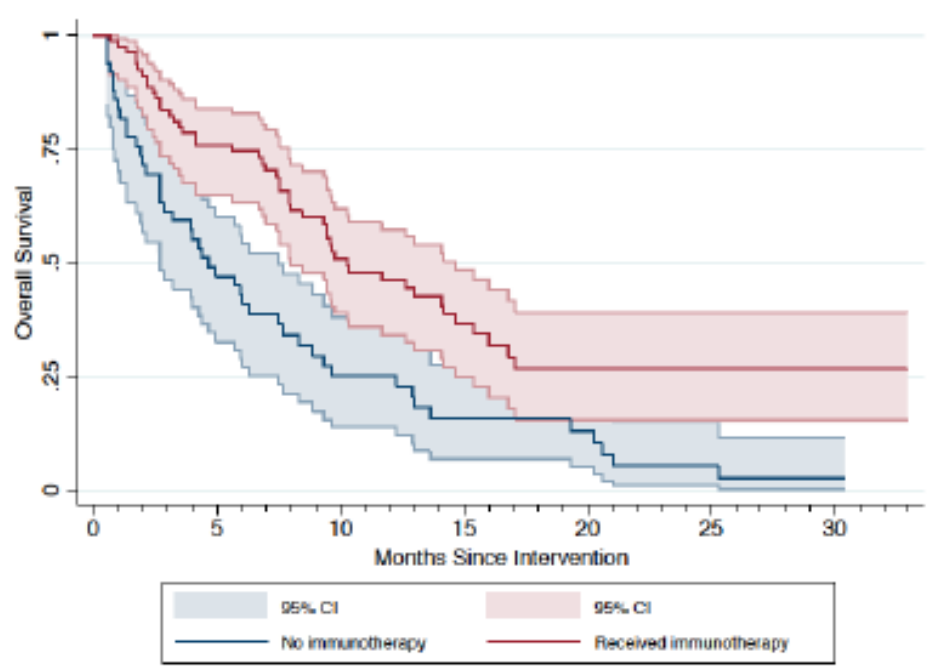

Figure 2

Post-intervention survival in patients comparing various interventions.

\section{Supplementary Files}

This is a list of supplementary files associated with this preprint. Click to download.

- STROBEchecklistcohort.docx

- SupplementalFigures.docx

- SupplementalTable1.docx 